\title{
El sexo como estigma: María y Jesús en la literatura judía tardoantigua
}

Recibido: 2/6/2018. Aceptado: 14/11/2018.

\section{Resumen}

En este breve trabajo analizamos el modo en el que los judíos de la tardoantigüedad construyeron una imagen negativa de Jesús y de María. El estudio se centra en tres pasajes del Talmud de Babilonia y en un texto de la tradición Toldot Yeshu. Refiere también a fuentes cristianas que presentan referencias negativas similares atribuidas a judíos. Los pasajes analizados ponen en evidencia que los judíos crearon una imagen sexualizada tanto de María como de Jesús con el fin de desacralizar sus figuras.

\section{Sex as stigma: Mary and Jesus in late ancient Jewish Literature}

\begin{abstract}
The aim of this article is to briefly analyze the Jewish construction of a negative image of Jesus and Mary during Late Antiquity. By focusing on three passages of the Babylonian Talmud, one text of the Toldot Yeshu tradition and a number of Christian sources that revisit the negative references attributed to Jews, the study will assess to what extent the creation of a sexualized image of both characters, Mary and Jesus, helped to desacralize their figures.
\end{abstract}

\section{Introducción}

Cuando se indaga la polémica entre judíos y cristianos en la Antigüedad Tardía, se suelen analizar los textos producidos por estos últimos. La primera
Palabras clave

Literatura judía tardía María José Talmud de Babilonia Toldot Yeshu

Keywords

ancient Jewish literature Mary Joseph Babilonian Talmud Toldot Yeshu 
1. Reenviamos, para un resumen del problema documental en torno al judaísmo tardoantiguo, a Laham Cohen (2018:5-14).

2. La Mishná es un corpus legal rabínico compilado entre finales del siglo | d.C. y principios del III d.C. En torno a la literatura rabínica en general, véase Strack; Stemberger (1996).

3. La Tosefta contiene los mismos tratados que la Mishnáy, en muchos casos, la sigue al pie de la letra. Ciertamente no es igual, pero su estructura e idiosincrasia es similar. Fue compilada en una temporalidad apenas posterior, hacia el siglo III d.C.

4. El Yerushalmies un extenso comentario de algunos tratados de la Mishná. Se supone, aunque existen intensos debates, que fue compilado hacia los siglos V-V en la Tierra de Israel. Aunque menos que respecto al Talmud de Babilonia, se ha debatido el nivel de intervención de los editores finales del texto sobre las tradiciones orales que dice recopilar. 5. Israel Yuval (2006) ha insistido en que existía una obsesión rabínica en el cristianismo y que la mayor parte de a literatura producida por los rabinos se orientó a responder al fenómeno cristiano... (Continúa en página 61.)

6. El Bavlícomenta diversos tratados de la Mishnáy fue editado entre los siglos VI y VII en Mesopotamia. Establecer el impacto de los editores

finales del texto sobre la tradición compilada es muy difícil. Volveremos sobre este aspecto más adelante.

7. La tradición denominada Toldot Yeshu se compone de historias en las cuales el nacimiento, la vida y la muerte de Jesús son explicadas-generalmente parodiadas- desde una perspectiva judía... (Continúa en página 61.)

8. Vale la pena aclarar que, dentro de a escasez de testimonios relacionados a Jesús en la literatura rabínica, estas referencias a la sexualidad de Jesús y de María ocupan un lugar importante.

9. En torno a Jesús y la literatura rabínica han existido diversos trabajos desde el siglo XX hasta la actualidad. Los más importantes, para dar un breve selección, son Herford (1903), Klausner (1926), Goldstein (1950)، Lauterbach (1951), Bammel (1967), Maier (1978), Kalmin (1994b), Jaffé (2003), Schäfer (2007) y Murcia (2014)

10. Tertuliano, De spectaculis, 30.6: Hic est ille, dicam, fabri aut quaestuariae filius, sabbati destructor, Samarites et daemonium habens. Texto latino tomado de Turcan (1986:325-326). Todas las traducciones del latín son nuestras.

11. En torno al tema véase a Horbury (1998). En general sobre Tertuliano y los judíos, véase, entre otros, Dunn (2008) y Binder (2012).

12. Mucho se ha escrito sobre la figura de Pantera. Un buen resumen de ello en Murcia (2014:55-98).

13. Orígenes, Contra Celso, I.32. Texto tomado de la edición de Markovich (2001:33). Todas las traducciones del griego son nuestras. Orígenes ya había anticipado el tema, en el marco de la prosopopeya del judío, en

1.28. Sobre Orígenes y los judíos, De Lange (1978) y Drake (2013:38-58).

14. Orígenes, Contra Celso, I.32:

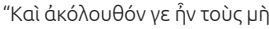

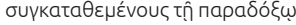

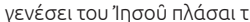

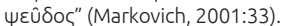

razón es que solo han llegado escasos materiales judíos de la Antigüedad Tardía, excepto en el espacio Palestino y en el Mesopotámico (y en menor medida, en el egipcio). ${ }^{1}$ Por otra parte, incluso en estas áreas, la existencia de referencias anticristianas en la literatura judía es exigua. Para dar algunos ejemplos, la Mishná ${ }^{2}$-el primer corpus rabínico de peso- no posee ninguna mención directa al cristianismo, mientras que en la Toseft ${ }^{3}$ hallamos solo una y en el aún más extenso Talmud de Jerusalén (Yerushalmi a partir de aquí) ${ }^{4}$ solo dos. Cierto es que existen pasajes en los cuales algunos críticos han encontrado ecos del cristianismo o ataques indirectos a este, pero no hay certezas en relación a tales referencias. ${ }^{5}$

A lo largo de esta breve presentación examinaremos algunas de las escasas referencias al cristianismo en la literatura rabínica -principalmente en el Talmud de Babilonia (Bavlí desde aquí) ${ }^{6}$ - y en una narrativa perteneciente a la tradición conocida como Toldot Yeshu. ${ }^{7}$ Pondremos el foco en los pasajes donde las figuras de Jesús y de María fueron construidas enfatizando su vinculación con la sexualidad. ${ }^{8}$ Huelga decir que no aspiramos a encontrar ni a la María ni al Jesús histórico, sino a comprender la imagen que ciertos grupos judíos de la Antigüedad Tardía construyeron en torno a ellos. ${ }^{9}$

Antes de avanzar es pertinente revisar algunos textos cristianos que parecen haber reflejado ideas, producidas por judíos, contra María y Jesús en torno a la sexualidad. Tertuliano es un buen punto de partida. Afirmó, en De spectaculis 30.6, en referencia a un Cristo triunfante: "'Este es él', diré, 'el hijo de un carpintero o de una meretriz; el destructor del shabat, el samaritano, el que posee al demonio'"' ${ }^{10}$ El pasaje, en realidad, no es simple de analizar porque si bien la referencia al shabat -y el propio contexto- parece indicar que Tertuliano está polemizando con los judíos, el texto se relaciona con el juicio final y parece implicar, también, a los paganos. ${ }^{11}$

Mucho más clara es la famosísima mención a Pantera ${ }^{12}$-supuesto soldado romano- como padre de Jesús, hallada en el Contra Celso (I.32) de Orígenes:

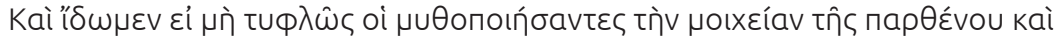

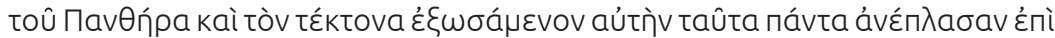

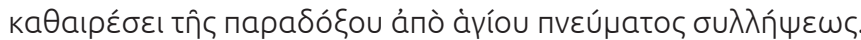

Veamos si los que compusieron a ciegas la fábula del adulterio de la virgen con Pantera y del carpintero que la echa de su casa, no inventaron todo eso para derribar la concepción extraordinaria por obra del Espíritu Santo. ${ }^{13}$

Es importante remarcar que, en la lógica del alejandrino, la explicación de tal historia era clara: "Era esperable que quienes no aceptaran el nacimiento milagroso de Jesús inventaran una mentira."14 Ciertamente, atacar la virginidad de María y, más aún, asociarla a un hecho de infidelidad, la mancillaba. Más allá del desarrollo que haya tenido para el período la idea de virginidad mariana, la acometida apuntaba a lograr la desacralización de ella y, por elevación, la de Jesús. Debe resaltarse, no obstante, que Orígenes respondía a Celso, quien ponía en boca de un judío la asociación entre el soldado romano y María, por lo que la referencia a Pantera -si creemos en esta cadena de transmisión- se remonta hasta los judíos del siglo II d.C.

Eusebio -sin referir explícitamente a los judíos- comentó que existían historias que sostenían que Jesús había sido el hijo de una pantera o de un hombre 
así llamado. ${ }^{15}$ Ya hacia fines del siglo IV, Epifanio volvió a referir a la historia de Pantera -afirmando que en realidad el abuelo de Jesús tenía por sobrenombre Pantera- aunque tampoco mencionó a los judíos como los difusores de la narrativa. ${ }^{16}$

Ahora bien, estas referencias cristianas en torno al comportamiento de María encuentran un correlato en la literatura judía de la Antigüedad Tardía. No solo ello, el propio Jesús aparece asociado, en distintas secciones del Talmud, a una conducta sexual inapropiada. Veamos, ahora sí, los textos.

\section{María y Jesús ante la sexualidad en la literatura judía tardoantigua}

Antes de comenzar es necesario insistir en la complejidad que implica trabajar con la literatura judía tardoantigua. En efecto, si nos ceñimos a los textos rabínicos -sobre todo a los talmudim- encontramos que se presentan como compilaciones de eventos y declaraciones de rabinos que abarcan un arco temporal que comienza en el II a.C. y termina aproximadamente hacia el cierre de cada Talmud. Por tal razón, no existe consenso académico en cuanto a la veracidad de dichos y hechos adjudicados a los rabinos. Por una parte, encontramos a quienes aceptan que la transmisión oral mantuvo con relativa estabilidad el contenido construido en cada época referida por el propio texto talmúdico. ${ }^{17}$ Por la otra, se ha impulsado la tesis de que es posible detectar, en cada tratado, un fuerte trabajo editorial que seleccionó, modificó, direccionó (e incluso creó) tradiciones, siempre acorde a la propia temporalidad de la edición final. ${ }^{18}$ Por supuesto hay quienes han optado por buscar un equilibrio entre edición final del texto y transmisión de tradición previa, aunque no han podido marcar con claridad, desde nuestro punto de vista, qué secciones reflejan el tiempo que dicen reflejar y cuáles marcan la influencia de los editores tardíos. ${ }^{19}$

Similar problema de datación existe para los textos pertenecientes a la tradición Toldot Yeshu, cuyo lugar de origen y momento preciso de producción, como ya anticipamos, continúan siendo debatidos. ${ }^{20}$ Existen, en efecto, posiciones verdaderamente dispares: Para Smelik (2009) estaríamos ante una tradición textual nacida en la Palestina del siglo III, mientras que para Sokoloff (2011) los textos de Toldot Yeshu que llegaron a la Genizá habrían surgido hacia mediados del primer milenio en el mundo babilónico.

Si bien no profundizaremos, por economía de espacio, en estas cuestiones ligadas a la datación de los textos rabínicos (y no rabínicos), las tendremos en cuenta al momento de reflexionar sobre las imágenes de María y Jesús en el Talmud.

Comencemos, entonces, por las referencias halladas en el Bavlí. Leemos en $b$ Shabat 104b y en B Sanedrín 67a:

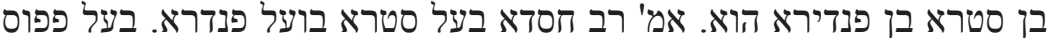

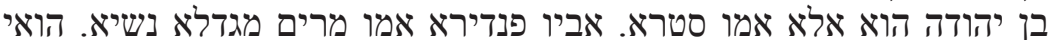 כידאמרי בפום בדיתא סטת דא מבעלה נשיא}

¿Ben Stará fue el hijo de Pandira? Rab Hisdá dijo: "El marido fue Stará y el amante fue Pandera". ¿Pero el marido no fue Pappos ben Yehuda y su madre Stará? Su padre fue Pandira y su madre Miriam M'gad'la N'shaia ${ }^{21}$. Esto es lo que se dice en Pumbedita acerca de ella: "Esta se desvió de su marido". 22
15. Eusebio, Eclogae propheticae, 3.10. Rechazaba la acusación -mediante la utilización de Os. 5.14- considerando que el mismo Jesús fue la pantera, en el mismo sentido en el que el texto bíblico mencionó una pantera en lugar de un león. Jerónimo, en Commentariorum in epistolam ad Titum 3.9, deslizaba, indirectamente, que los judíos se burlaban de la genealogía de Jesús. Una mirada valiosa sobre Eusebio y los judíos en Irshai (2012). En torno a Jerónimo, Stemberger (1993) y Lössl (2002).

16. Epifanio, Panarión, 78.7.5-10. Afirmó que José era hijo de un tal Jacobo, cuyo sobrenombre era Pantera. Sobre Epifanio y los judíos, véase a Lössl (2002).

17. Entre los autores que sostienen esta postura destaca Kalmin (1994; 2006).

18. Jacob Neusner ha sido quien ha impulsado la línea hoy conocida como tesis documentaria. Si bien obtuvo un alto grado de consenso en su momento, actualmente se encuentra fuertemente cuestionada. Entre las muchas obras de Neusner, véase 1987 y 2008.

19. David Halivni (2013) consideró la existencia de un grupo específico de editores anónimos del Bavlí, los stammaim, que habrían reutilizado y reformulado tradiciones previas, así como también adicionado puntos de vista propios. Su posición, no obstante, es resistida por muchos especialistas. Véase también Rubenstein (2003).

20. Reenviamos nuevamente a los trabajos de Horbury (1971) y Di Segni (1985), y a la compilación de Schäfer et alii (2011).
21. Las palabras מגדלא נשיא han sido interpretadas de diversa forma. Véase, entre otros trabajos, a Visotzky (1995). Reenviamos nuevamente a Murcia (2014:57-92) para una condensación de las polémicas sobre este nombre. 22. Tomado del ms. Oxford Opp. add. fol. 23 (ss. XIV-XV). Todas las traducciones de los textos rabínicos son nuestras. 
23. Hay mucha variabilidad en torno al modo en el cual Pantera/Pandira/ Pandera se escribe en cada manuscrito.

24. Durante la Baja Edad Media y el período moderno las autoridades cristianas intervinieron los textos judíos censurando las referencias hostiles, tanto directas como indirectas, hacia el cristianismo.

25. Este pasaje puede ser hallado también en los mss. Vaticano 108 (ss. XIII-XIV), Vaticano 487.8 (s. XIII) y Munich 95 (1348) para b Shabat. El pasaje de b Sanedrín aparece en Florencia II.1.9 (ss. XII-XIII), Reuchlin 2 (s. XIII), Munich 95 (1348), Klosterneuburg fragm. 128 (s. XIV) y Herzog I (posterior a 1565).

26. Otras aproximaciones a este pasaje en Stourdzè (1926), Lauterbach (1951:481-490), Gero (1994), Kalmin (1994b:156), Boyarin (1999:24-26 y passim), Fontana (2003), Jaffé (2003), Schäfer (2007:34-40) y Murcia (2011 y 2014:377-421).

27. Aquí el texto muestra ambigüedad, dado que אכסניא puede significar posada, posadera o, incluso, hospitalidad. Deriva del término griego ¿zvía. Es interesante que, en la línea previa, la referencia es a préstamo del latín hospitium.

28. Texto tomado del ms. Florencia II.1.9 (ss. XII-XIII). Como en el caso anterior, la referencia a Jesús no

aparece en versiones posteriores a la censura. Puede encontrarse, también, en Múnich 95 (1348), Reuchlin 2 (s. XIII) y Herzog I (posterior a 1565) mientras que el pasaje paralelo, en $b$ Sotá 47a, se halla en Múnich 95 (1348), Heb d. 20 de Oxford (s. XIII), Ebr. 110 del Vaticano (1380) y en FRI de la colección privada Lehmann (ss. XIII-XIV).
No es este el espacio para analizar este texto en detalle dado que lo hemos realizado en otra ocasión (Laham Cohen, 2016). Baste señalar que, sea que interpretemos aquí desconocimiento e ignorancia de los rabinos o que consideremos que es un deliberado intento de construir la incontinencia de María, el texto se orienta claramente a poner en tela de juicio la conducta moral de María. Resalta, por un lado, la existencia de un amante, más allá de debatir quién fue. Por el otro, considera, categóricamente, que María fue infiel a su marido. Nótese, también, la referencia a Pantera -aquí como Pandira ${ }^{23}$ - hecho que prueba, entendemos, la difusión de tal narrativa en la Antigüedad Tardía. Ello no implica mecánicamente que la historia haya sido creada en medios judíos -cuestión que, desde nuestro punto de vista, es verosímil- pero sí confirma la circulación de tal historia entre estos.

Como anticipamos, datar estos pasajes talmúdicos es difícil. El personaje mencionado-Hisdá- puede ser ubicado-aunque dependemos plenamente de evidencia intratalmúdica o rabínica muy tardía- hacia el siglo III d.C., en Babilonia. Saber si efectivamente él pronunció tales palabras o si los editores finales del texto las pusieron en su boca es imposible. Lo único seguro es que estas frases, compiladas o inventadas, fueron aceptadas hacia los siglos VI-VII, momento estimado del cierre del Bavlí. Para tornar más difícil la cuestión, estos pasajes solo pueden ser recuperados a partir de manuscritos no censurados, ${ }^{24}$ tal como el que hemos utilizado, perteneciente a una temporalidad cercana a los siglos XIV-XV. Lamentablemente, no disponemos, para este tratado, de manuscritos anteriores al siglo XIII. ${ }^{25}$ Más allá de estos problemas, es importante retener que, al menos para el momento en el que Bavlí fue compilado, María era considerada por ciertos grupos judíos como una mujer infiel que había tenido algún tipo de relación ilícita con Pantera. ${ }^{26}$

Pero Jesús es manchado, siempre en la lógica de la narrativa rabínica, no solo por ser el hijo de la volátil María. En b Sanedrín 1o7b y en $b$ Sotá $47 a$ leemos:

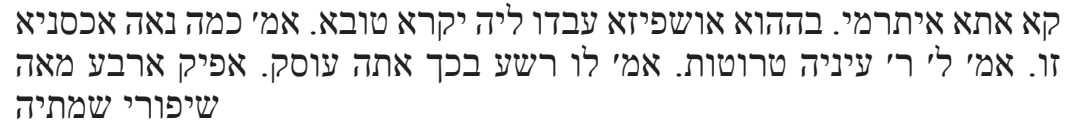

[Yoshua ben Perajiá] se levantó y se fue. Se encontró en cierto hospicio en el cual lo sirvieron con gran honra. Dijo: "¡Qué bella posada/posadera ${ }^{27 ! " . ~ E ́ l ~}$ [Jesús] le dijo al rabino "Sus ojos son lagañosos". [Yoshua ben Perajiá] le dijo "¡Malvado! ¿De estas cosas te ocupas?" Sonó 400 cuernos y lo excomulgó. ${ }^{28}$

Esta narración se encuentra dentro de una historia más amplia que, luego de este malentendido y otro sucesivo que no analizaremos aquí por economía de espacio, desencadena -en la lógica talmúdica- la herejía cristiana. Como hemos afirmado en otro trabajo (Laham Cohen, 2017), es posible ver en el altercado en torno a la posada/posadera un cuestionamiento a la espiritualidad de Jesús. Este, en lugar de interpretar a su maestro, quien refería al espacio donde era atendido, posa la mirada en la mujer y, peor aún, la juzga desde un punto de vista estético. Así, el mesías cristiano no solo falla en comprender el mensaje de quien lo dirige, sino que escruta con su mirada a quien lo atiende, en un gesto vinculado a la carnalidad.

En cuanto a la datación del evento narrado, es sintomático de la falta de precisión e interés histórico del Bavlí el hecho de que Yoshua ben Perajía vivió, según evidencia intratalmúdica, entre los siglos II y I a.C., cuestión que, para 
dar un ejemplo, llevó a George Mead (1903), sin análisis crítico alguno, a considerar el nacimiento de Jesús un siglo antes de lo comúnmente aceptado. ${ }^{29}$ En virtud de ello, creemos que atribuir historicidad al evento, así como también adjudicarlo al contexto egipcio/palestino que lo enmarca, es absolutamente improcedente. Nuevamente, solo podemos afirmar que, hacia el momento en el que el Bavlí fue escrito, se recuperó, se inventó o se reformuló una historia que presentaba a un Jesús no espiritual.

Existe un último pasaje del Bavlí que podría vincularse a la sexualidad de Jesús pero, lamentablemente, es muy opaco. Se trata de un cortísimo texto que aparece en $b$ Sanedrín 10за y $b$ Berajot 17b. Leemos en $b$ Sanedrín 10зa:

\section{לא תמ(נ)[צ]א אשתך ספק בשעה שתבא מן הדרך. דבר אחר לא תאונה אליך

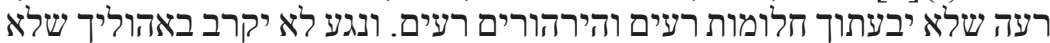 יהיה לך בן או תלמיד שמקדים והיחורים תו תבשילו ברבים כגון ישו הנוצרי לאולי}

Que no encuentres a tu mujer en un estado incierto de impureza al retorno de un viaje. Otra interpretación: No te sobrevendrá mal ${ }^{30}$ que no seas afectado por sueños y malos pensamientos; ni plaga tocará tu morada, ${ }^{31}$ que no tengas un hijo o un discípulo que queme la comida públicamente como Jesús el nazareno (leshu hanotzri). ${ }^{32}$

La mención a quemar la comida públicamente ha generado confusión entre los especialistas. En general, se la ha considerado una referencia a la desviación de Jesús en términos de herejía. No obstante, Johann Maier (1978:66) -basándose en otros pasajes del Bavlí que vinculan comida al sexo- sugirió que la mención a la quema del alimento apuntaba al comportamiento sexual de Jesús. Tal perspectiva fue notoriamente potenciada por Peter Schäfer (2007:25-33), quien sumó a estos argumentos la idea de que la mujer impura al retorno de un viaje es un problema porque impide el contacto sexual y que los sueños y malos pensamientos también podrían asociarse a cuestiones vinculadas al sexo. La hipótesis es verosímil y se condice con los otros pasajes analizados aunque desde nuestro punto de vista la referencia se acerca más a la idea de herejía que a la de inmoralidad sexual (Laham Cohen, 2013). ${ }^{33}$ En relación a la datación, los rabinos que aparecen asociados a este pasaje incluyen al ya mentado Hisdá. Seguimos sosteniendo, no obstante, la futilidad de insistir en datar estos eventos y referencias.

Es momento, ahora, de referirnos a un manuscrito que porta una historia enmarcada en la tradición Toldot Yeshu. Tal como anticipamos, la datación de este tipo de textos dista de ser fácil. Aquí trabajaremos con el ms. JTS 8998, en hebreo, considerado apenas posterior al grupo arameo más temprano. ${ }^{34} \mathrm{Al}$ igual que con el Bavlí, los manuscritos más antiguos que poseemos de Toldot Yeshu -hallados en la Genizá del Cairo- no son anteriores al siglo X. El contenido y el estilo de JTS 8998 se asemeja notoriamente a tales materiales. Leemos:

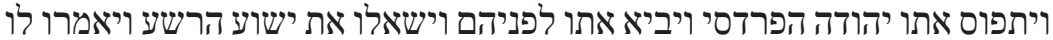

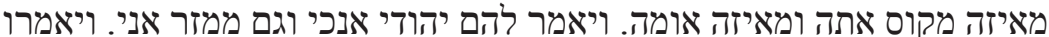

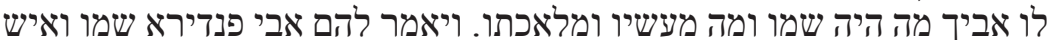

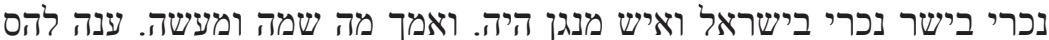
מרים שמה והיא גודלת שער נשים גדיש ניולות ומת אבי ובא יוסף ע?רה ומעה ונשא אתה להם

Y Judá el hortelano lo capturó y lo trajo delante de ellos [de los jueces] e interrogaron a Jesús [Yeshua] el malvado y le dijeron: "¿De dónde vienes? ¿Y de qué nación?". Y les dijo: "Judío soy. Y yo también soy un bastardo". Ellos
29. Debe resaltarse también que aquí existe una clara rabinización del pasado por parte de los compiladores/ editores del Talmud, dado que para el período en el que supuestamente vivi Yoshuano existín rabinos, mivó Yoshua existín rat menos tal como se constituyeron en movimiento posterior al siglo II d.C.

30. Salmos, 10:91

31. Ibid.

32. Tomado del ms. Florencia Il.1.9 (ss. XII-XIII). El texto también aparece también en Múnich 95 (1348), Reuchlin 2 (s. XIII) y Herzog I (posterior a 1565). Para b Berajot la referencia aparece, aunque a veces censurada, en Florencia II.1.7 (1177). París 671 (s. XV). Múnich 95 (1348) y Oxford add. fol. 23 (ss. XIV-XV).

33. Otros análisis sobre el pasaje pueden ser hallado en: Goldsten (1950:116117), Lauterbach (1951:488; 501), Maier (1978:66-67) y Schäfer (2007:25-33).

34. Meerson; Schäfer (2014:1.29) consideran que JTS 8998, el manuscrito en hebreo más antiguo de Toldot Yeshu desde su punto de vista, debe ser datado entre los siglos X y XIII, apenas posteriormente al grupo arameo más temprano. A su vez, el momento de producción original de los textos en arameo ha sido establecido, por especialistas como (2011), hacia mediados de primer milenio. Referencias a la concepción inmoral de Jesús en el denominado Grupo I también en mss. JTS 6312 y RNL EVR 1.274, aunque se trata de piezas muy tardías (ca. XVI-XVII). 
35. El pelo largo es sinónimo de falta de recato. El texto no es claro y nos remite, aunque tangencialmente, a las palabras M'gad'la N'shaia que hemos visto en b Shabat 104b y en B Sanedrín 67a. La novedad es que aquí aparece el término שער (pelo), que también se encuentra en la lectura que hizo Rashi (1040-1105) sobre las palabras M'gad'la N'shaia en os pasajes antes mencionados. Es difícil dirimir si el pasaje de Toldotes posterior o anterior a Rashi aunque, desde estra perspectiva, fue producido en un tiempo más temprano. Véase, para las explicaciones sobre este aspecto, Visotzky (1995) y Murcia (2014:57-92). 36. Ms. JTS 8998. Texto tomado de la edición Meerson; Schäfer (2014:60).

37. Sobre la falta del control de cuerpo como un aspecto criticable para el mundo grecolatino: Dover (1974), Cohen (1991), Richlin (1992), Rouselle (1993), Hawkes (2004:2441) y Skinner (2005). Para el Antiguo Testamento, Klawans (2000:21-62) y Davisdon (2007). Por último, para y 1992b), Satlow (1995), Fonrobert (2000), Klawans (2000:92-117), Hayes (2002) y Koltun-Fromm (2010). Un buen resumen de la explosión de estudios sobre el cuerpo y la sexualidad en el Talmud en Fonrobert (2005). le dijeron: “¿Cuál es el nombre de tu padre, qué cosas ha hecho y de qué se ocupa?". Les dijo: "El nombre de mi padre es Pandera, fue un extranjero, un extranjero en Israel y un músico". "¿Y tu madre? ¿Cuál era su nombre y qué ha hecho?". El respondió "Su nombre es Miriam y se dejaba crecer su pelo de mujer adulta. ${ }^{35}$ Cuando mi padre murió/se fue y José ¿la ayudó? y se casó con ella". 36

Este pasaje se encuentra claramente relacionado con Orígenes y con $b$ Shabat 104b y b Sanedrín 67a. Vuelve a aparecer la figura de Pantera, la idea de una María sin recato y la noción de Jesús como un hijo concebido ilícitamente. Debemos reconocer, no obstante, que en los manuscritos de Toldot hallados en la Genizá -a diferencia de otros textos más tardíos de la misma tradición- no hay referencias a la concepción de Jesús ni a aspectos relacionados a su sexualidad. De todos modos, no es inverosímil que el texto contenido en JTS 8998 haya sido producido hacia mediados del primer milenio en el marco de una tradición que, como vimos, se detecta tanto en fuentes judías como cristianas.

\section{Reflexiones en torno a la sexualización de María y de Jesús en la literatura judía tardoantigua}

Hemos visto en estas escasas páginas que existía -en medios judíos- una serie de constructos discursivos orientados a deslegitimar las figuras de María y de Jesús a través de acusaciones relacionadas a la moral. Ello puede comprobarse no solamente a través de la propia literatura judía del período -con mucha cautela por los problemas de datación referidos- sino también en materiales producidos por los cristianos en la misma etapa. Según nuestro punto de vista, este tipo de historias circularon desde temprano -la prosopopeya del judío en Celso podría funcionar como terminus ante quem- aunque, desde las fuentes judías, solo podemos visibilizarlas con claridad desde mediados del milenio, en el cálculo más optimista.

Es pertinente preguntarse por qué razón los judíos enfatizaban -en las llamativamente escasísimas referencias al cristianismo que se encuentran en la literatura judía tardoantigua (rabínica y no rabínica)- el comportamiento carnal de María y de Jesús. Aquí nuestras respuestas incluyen tres andariveles explicativos que se complementan. El primero, el más simple pero no por ello menos importante, es que en la Antigüedad -no solo en el marco del judaísmo o del cristianismo sino también en la religiosidad romana clásica- la falta de control sobre el cuerpo era un aspecto usualmente utilizado como herramienta para difamar a adversarios políticos y/o religiosos. ${ }^{37}$ En segundo término, tornar a María una mujer carnal implicaba un certero golpe a la imagen de virginidad que la mayoría de los cristianismos impulsaban. En la misma línea, hacer de Jesús un hombre falible y pedestre ponía en tela de juicio no solo su figura sino la de la ascesis cristiana, precisamente fuerte en regiones como Siria y parte del mundo persa donde existían grupos cristianos muy apegados a formas radicales de continencia. Así, sexualizar a Jesús y a María pudo haber operado como un arma clásica pero a la vez específicamente hiriente para quienes enfatizaban la espiritualidad en la teología cristiana.

Pero a estas dos explicaciones se puede sumar, como anticipamos, una tercera que, si bien más hipotética, creemos verosímil. Entendemos que la atribución de conductas inmorales a dos personajes centrales del cristianismo es una reversión intencional de la construcción cristiana del judío como sujeto carnal. 
Es sumamente conocido por quienes han frecuentado la literatura cristiana tardoantigua que, dentro del arsenal de tópicos adversus Iudaeos, aparece la idea de carnalidad judía. Carnalidad en dos sentidos: por un lado, comprensión literal de la ley producto de la falta de espiritualidad y, por el otro, comportamiento sexual desmedido. Podemos debatir si esta mirada nació como efecto del conocimiento cristiano de una actitud rabínica más abierta hacia el sexo, tal como lo sugirió Boyarin (1993), o si fue simplemente una estrategia discursiva para deslegitimar a los judíos por no aceptar la interpretación cristiana del Antiguo Testamento (Drake, 2013). Pero, sea por una u otra explicación, lo cierto es que los judíos eran sindicados como inmorales por los cristianos. En esta línea, sexualizar a María y a Jesús aparece como una represalia destinada a invertir el par carnalidad/espiritualidad impulsado por el cristianismo. ${ }^{38}$

Enfocar la polémica entre judíos y cristianos desde las voces judías -tanto en textos cristianos como en judíos- enriquece el panorama de la discusión entre ambos grupos religiosos tanto en la Roma tardía como en el mundo bizantino. Porque no solo nos permite conocer cómo atacaban y se defendían los judíos sino también echar algo de luz al diálogo y a la interacción entre comunidades religiosas.

\section{Notas}

5 Israel Yuval (2006) ha insistido en que existía una obsesión rabínica en el cristianismo y que la mayor parte de la literatura producida por los rabinos se orientó a responder al fenómeno cristiano. Daniel Boyarin (1999) también ha remarcado la influencia del cristianismo en la formación de la identidad rabínica. En la vereda opuesta encontramos a Alon Goshen-Gottstein (2003-2004) y a Adiel Schremer (2010), entre otros. (Viene de página 56.)

7 La tradición denominada Toldot Yeshu se compone de historias en las cuales el nacimiento, la vida y la muerte de Jesús son explicadas -generalmente parodiadas-desde una perspectiva judía. No son textos fáciles de datar dado que los manuscritos más antiguos fueron hallados en la Genizá del Cairo y pertenecen a los siglos IX y X d.C. No existe consenso, entonces, ni en torno el momento de producción original de tales narrativas ni en relación al espacio en el que se produjeron. En torno a esta tradición, véase, entre otros, Horbury (1971), Di Segni (1985) y Schäfer et alii (2011). Volveremos, más adelante, sobre el tema. (Viene de página 56.) 


\section{Q Bibliografía}

» Bammel, E. (1967). "Christian origins in Jewish Tradition", New Testament Studies 13/4, 317-335.

" Biale, D. (1992a). Eros and the Jews: From Biblical Israel to Contemporary America. Nueva York: Basic Books.

" Biale, D. (1992b) (ed.). From Intercourse to Discourse: Control of Sexuality in Rabbinic Literature. Berkeley: Center for Hermeneutical Studies.

" Binder, S. (2012). Tertullian, On Idolatry, and Mishnah Avodah Zarah. Questioning the Parting of the Ways between Chritians and Jews. Leiden - Boston: Brill.

» Boyarin, D. (1993). Carnal Israel. Reading Sex in Talmudic Culture. Berkeley: University of California Press.

» Boyarin, D. (1999). Dying for God. Martyrdom and the Making of Christianity and Judaism. Stanford: Stanford University Press.

" Cohen, D. (1991). Law, Sexuality, and Society: The Enforcement of Morals in Classical Athens, Cambridge: Cambridge University Press.

"Davidson, R. (2007). Flame of Yahweh: Sexuality in the Old Testament. Peabody: Hendrickson.

"De Lange, N. (1978). Origen and the Jews. Studies in Jewish Christian relations in third-century Palestine. Cambridge: Cambridge University Press.

»Di Segni, R. (1985). Il Vangelo del Ghetto. "Le Storie di Gesù": Leggende e documenti della tradizione medievale ebraica. Roma: Newton Compton editori.

» Dover K. (1974). Greek Popular Morality in the Time of Plato and Aristotle. Berkeley: University of California Press.

»Drake, S. (2013). Slandering the Jew: Sexuality and Difference in Early Christian Texts. Pennsylvania: University of Pennsylvania Press.

» Dunn, G. (2008). Tertullian's Adversus Iudaeos. A Rethorical Analysis. Washington: The Catholic University of America Press.

» Fonrobert, C. (2000). Menstrual Purity. Rabbinic and Christian Reconstructions of Biblical Gender. Stanford: Stanford University Press.

» Fonrobert, C. (2005). "On Carnal Israel and the Consequences: Talmudic Studies since Foucault", Jewish Quarterly Review 95/3, 462-469.

" Fontana, R. (2003). "Un discepolo di nome Gesù (Sanhedrin 107b)", Bibbia e oriente 45/3, 165-175.

"Gero, S. (1994). "The Stern Master and His Wayward Disciple: A 'Jesus' Story in the Talmud and in Christian Hagiography", Journal for the Study of Judaism 25/2, 287311.

» Goldstein, M. (1950). Jesus in the Jewish Tradition. Nueva York: The Macmillan Company.

» Goshen-Gottstein, A. (2003-2004). "Polemomania. Reflexiones metodológicas en el estudio de la controversia judeo-cristiana entre los sabios del Talmud y Orígenes sobre la interpretación del Cantar de los Cantares", Jewish Studies 42, 119-190 (en hebreo). 
" Halivni, D. (2013). The Formation of the Babylonian Talmud. Nueva York: Oxford University Press.

» Hawkes, G. (2004). Sex and Pleasure in Western Culture. Malden: Polity Press.

" Hayes, C. (2002). Gentile Impurities and Jewish Identities: Intermarriage and Conversion from the Bible to the Talmud. Oxford: Oxford University Press.

» Herford, T. (1903). Christianity in Talmud and Midrash. Londres: Williams \& Norgate.

» Horbury, W. (1971). A Critical Examination of the Toledoth Yeshu. Cambridge (tesis doctoral no publicada).

" Horbury, W. (1998). "Tertullian on the Jews in the Light of De Spectaculis XXX, 5-6". En: Horbury, W. (ed.), Jews and Christians. In Contact and Controversy. Edimburgo: T \& T Clark, 176-179.

» Irshai, O. (2012). "Jews and Judaism in Early Church Historiography: The Case of Eusebius of Caesarea (Preliminary Observations and Examples)". En: Bonfil, R. et al. (eds.), Jews in Byzantium. Dialects of Minority and Majority Cultures. Leiden - Boston: Brill, 799-828.

" Jaffé, D. (2003). "Jésus dans le Talmud. Le texte sur Josué ben Parahyah et son disciple Jésus réexaminé", Pardès 35, 79-92.

" Kalmin, R. (1994a). Sages, Stories, Authors, and Editors in Rabbinic Babylonia. Atlanta: Scholars Press.

» Kalmin, R. (1994b). "Christians and Heretics in Rabbinic Literature of Late Antiquity", The Harvard Theological Review 87/2, 155-169.

" Kalmin, R. (2006). Jewish Babylonia between Persia and Roman Palestine: Decoding the Literary Record. New York: Oxford University Press.

» Klausner, J. (1926). Jesus of Nazareth. His Life, Times, and Teachings. Nueva York: The Macmillan Company.

" Klawans, J. (2000). Impurity and Sin in Ancient Judaism. Oxford: Oxford University Press.

» Koltun-Fromm, N. (2010). Hermeneutics of Holiness. Ancient Jewish and Christian Notions of Sexuality and Religious Community. Oxford: Oxford University Press.

» Laham Cohen, R. (2013). "La construcción de la no santidad. Jesús en b Sanedrín $103 a$ y b Berajot 17b", Temas Medievales 21, 181-220.

"Laham Cohen, R. (2016). "La confusión como estrategia retórica. María y Jesús en b Shabat 104b y b Sanedrín 67a", Antiquité Tardive 24, 285-305.

" Laham Cohen, R. (2017). "La mirada atrevida. Jesús en b Sanedrín 107b y la tópica Adversus ludaeos", Annali di storia dell'esegesi 34/2, 577-602.

"Laham Cohen, R. (2018). The Jews in Late Antiquity. Leeds: Arc Humanities Press.

" Lauterbach, J. (1951). "Jesus in the Talmud". En: AA.VV., Rabbinic Essays. Cincinnati: Hebrew Union College Press.

"Lössl, J. (2002). "Hieronymus und Epiphanius von Salamis uber das Judentum ihrer Zeit", Journal for the Study of Judaism 33/4, 411-436.

» Maier, J. (1978). Jesus von Nazareth in der talmudischen Überlieferung. Darmstat: Wissenschaftliche Buchgesellschaft.

" Markovich, M. (ed.) (2001). Origenes. Contra Celsum libri VIII. Leiden: Brill.

" Mead, G. (1903). Did Jesus Live 100 years B.C.? An Enquiry into the Talmud Jesus 
Stories, The Toldoth Jeschu, and some Curious Statements of Epiphanius - being a Contribution to the Study of Christian Origins. Londres: Theosophical Publishing Society.

» Meerson, M. y Schäfer, P. (eds. y trads.) (2014). Toledot Yeshu. Tübingen: Mohr Siebeck.

" Murcia, T. (2011). "Jésus adorateur d'une Brique? B. Sanhedrin 107B: l'épisode talmudique du séjour de Yeshu en Égipte", Revue des études juives 170/3-4, 369-398.

» Murcia, T. (2014). Jesus dans le Talmud et la littérature rabbinique ancienne. Turnhout: Brepols.

" Neusner, J. (1987). The Bavli and Its Sources: The Question of Tradition in the Case of Tractate Sukkah. Atlanta: Scholars Press.

» Neusner, J. (2008). Building Blocks of Rabbinic Tradition: The Documentary Approach to the Study of Formative Judaism. Lanham: University Press of America.

" Richlin, A. (1992). The Garden of Priapus. Sexuality and Aggression in Roman Humor. Nueva York - Oxford: Oxford University Press.

» Rouselle, A. (1993). Porneia: On Desire and the Body in Antiquity. Cambridge: Blackwell.

» Rubenstein, J. (2003). The Culture of the Babylonian Talmud. Baltimore - Londres: The Johns Hopkins University Press.

"Satlow, M. (1995). Tasting the Dish: Rabbinic Rhetorics of Sexuality. Atlanta: Scholars Press.

»Schäfer, P. (2007). Jesus in the Talmud. Princeton-Oxford: Princeton University Press.

"Schäfer, P. et alii (eds.) (2011). Toledot Yeshu. ("The Life Story of Jesus") Revisited. Tübingen: Mohr Siebeck.

» Schremer, A. (2010). Brothers Estranged. Heresy, Christianity, and Jewish Identity in Late Antiquity. Nueva York: Oxford University Press.

» Skinner, M. (2005). Sexuality in Greek and Roman Culture. Oxford: Wiley Blackwell.

"Smelik, W. (2009). "The Aramaic Dialect(s) of the Cairo Geniza Toldot Yeshu Fragments", Aramaic Studies 7, 2009, 39-73.

"Sokoloff, M. (2011). "The Date and Provenance of the Aramaic "Toledot Yeshu" on the Basis of Aramaic Dialectology". En: Schäfer, P. et alii (eds.) (2011), Toledot Yeshu. ("The Life Story of Jesus") Revisited. Tübingen: Mohr Siebeck, 13-26.

"Stemberger, G. (1993), "Hieronymus und die Juden seiner Zeit", En: Stemberger, G. (ed.), Judaica Minora II. Tübingen: Mohr Siebeck, 347-364.

"Stourdzé, H. (1926). "La fuite en Égypte de Josue Ben Perahya", Revue des études juives 82, 135-156.

"Strack, H.; Stemberger, G. (1996). Introduction to the Talmud and Midrash. Minneapolis: Fortress Press.

» Turcan, M. (ed.) (1986). Tertullien. Les Spectacles. Paris: Du Cerf.

"Visotzky, B. (1995). "Mary Maudlin among the Rabbis". En: Visotsky, B. (ed.), Fathers of the World: Essays in Rabbinic and Patristic Literatures. Tübingen: Paul Siebeck, 85-92.

» Yuval, I. (2006). Two Nations in Your Womb. Perception of Jews and Christians in Late Antiquity and the Middle Ages. Berkeley - Los Angeles - London: University of California Press. 